\title{
The Chemical Compounds from Degradation of Profenofos and Malathion by Indigenous Bacterial Consortium
}

\author{
Slamet Isworo ${ }^{1 *}$ (D) and Poerna Sri Oetari² \\ ${ }^{1}$ Department of Environmental Health, Universitas Dian Nuswantoro, Jl. Imam Bonjol 207, \\ Semarang 50131, Central Java, Indonesia. \\ ${ }^{2}$ Environmental Impact Assessment. PT. Mitra Adhi Pranata. Jl. Cemara IV No.45, Padangsari, \\ Banyumanik, Semarang, Indonesia.
}

\begin{abstract}
The Indonesian Pesticide Regulations state that Malathion and Profenofos have been restricted in their use for agriculture because of is bioaccumulative in ecological systems. Cleaning technology using microorganisms is an effective solution for cleaning pesticide residues. This study aims to identify the bacteria that degrade and the degradation process of Malathion and Profenophos into non-toxic compounds. The research method was experimental, identification of bacteria by 16S-rRNA gene analysis, degradation ability by GC MS. The results of phylogenetic tree analysis showed that the tested bacteria were closely related to Oceanobacillus iheyenis (RPL1) and Exiquobacterium profundum (RPL5) with a similarity level of $87 \%$ and $99 \%$. The two bacteria are used as a consortium of test bacteria. The results of degradation based on the observation chromatogram $\mathrm{T}=0$ showed that the Malathion compound $\mathrm{C}_{10} \mathrm{H}_{19} \mathrm{O}_{6} \mathrm{PS}_{2}$ or butanedioic acid [(dimethoxyphosphinothioyl) thio]) was detected at peak 4, real-time $=19,675$, area\% $=7.37$ and Profenofos compound $\mathrm{C}_{11} \mathrm{H}_{15} \mathrm{BrClO}$ PSO-(4-Bromo-2-chlorophenyl) o-ethyl s-propyl thiophosphate, peak 8 , real-time $=23,957$, area\% $=6.91$. Likewise, the chromatogram results at $\mathrm{T}=96$ were still detected Malathion ((dimethoxyphosphinothioyl) thio) at peak 14, real-time = 19,675 , area\% $=2.25$, and Profenofos (o- (4-Bromo-2-chlorophenyl)) o - ethyl. $s$ - propyl thiophosphate) peak $=22$ real-time $=23,951$, area $\%=2.2$. However, the observation of $\mathrm{T}=192$ hours, Malathion and Profenofos compounds were not detected. The conclusion showed that the consortium bacteria were able to completely degrade Malathion and Profenophos within 192 hours.
\end{abstract}

Keywords: Consortium bacteria, Exiquobacterium profundum, Oceanobacillus iheyenis, Biodegradation, Malathion, Profenofos

*Correspondence: slamet.isworo@dsn.dinus.ac.id

(Received: April 18, 2021; accepted: May 22, 2021)

Citation: Isworo S, Oetari PS. The Chemical Compounds from Degradation of Profenofos and Malathion by Indigenous Bacterial Consortium. J Pure Appl Microbiol. 2021;15(2):897-914. doi: 10.22207/JPAM.15.2.47

(C) The Author(s) 2021. Open Access. This article is distributed under the terms of the Creative Commons Attribution 4.0 International License which permits unrestricted use, sharing, distribution, and reproduction in any medium, provided you give appropriate credit to the original author(s) and the source, provide a link to the Creative Commons license, and indicate if changes were made. 


\section{INTRODUCTION}

Pesticides are widely used to increase agricultural yields, plantations, forestry production, but pesticides can have a negative impact on the non-target environment. Pesticide pollution needs to be controlled because it can damage the ecological balance ${ }^{1}$. Malathion and Profenofos are types of pesticides that are widely used by farmers around Lake Rawa Pening in Central Java, Indonesia, even though these pesticides have been banned especially for rice cultivation based on Regulation of the Minister of Agriculture of the Republic of Indonesia Number 39 / Regulation of the Minister of Agriculture / SR.330 / 7 / 2015 ${ }^{2}$. It is proven that Profenofos is widely used by farmers around Rawa Pening (50\%), then Carbamate (16\%), Deltamethrin (8\%), Imidacloprid (6\%), Fentoat (5\%), Carbosulfan (5\%), Carbofuran (5\%) and Lamda Sihalotrin (4\%). The results of the Profenofos residue analysis in the waters of Rawa Pening ranged from $0.021 \mathrm{ppm}-0.08 \mathrm{ppm}$, the sediments ranged from $0.12 \mathrm{ppm}-0.28 \mathrm{ppm}$ while the Malathion residue in the waters ranged from $0.0366 \mathrm{ppm}-0.0521 \mathrm{ppm}$ and in sediments ; $0.0567 \mathrm{ppm}-0.12 \mathrm{ppm}^{3}$, is above the specified threshold $\leq$ of $0.01 \mathrm{ppm}^{4}$. Therefore, it is necessary to make efforts to clean the residue of Malathion and Profenofos which have long been exposed to the environment. Indigenous bacteria are developed as biological agents in modifying toxic residues into non-toxic compounds ${ }^{5}$

The degradation process of Malathion Diethyl (dimethoxythiophosphorylthio)succinate $\left(\mathrm{C}_{10} \mathrm{H}_{19} \mathrm{O}_{6} \mathrm{PS}_{2}\right)$ in aquatic systems will be degraded to monocarboxylic acid-dimethyl monocarboxylic acid - dicarboxylic acid - dimethyl dicarboxylic aciddicarboxylic acid- $\mathrm{CO}_{2}{ }^{6}$. Malathion fragmentation in the environment will become maloxon $\left(\mathrm{C}_{10} \mathrm{H}_{19} \mathrm{O}_{7} \mathrm{PS}\right)$, malathion monocarboxylic acid $\left(\mathrm{C} \mathrm{H}_{15} \mathrm{O}_{6} \mathrm{PS}_{2}\right)$, and 2-mercaptosuccinic acid $\left(\mathrm{C}_{6} \mathrm{H}_{5} \mathrm{NO}_{2} \mathrm{~S}\right)$ are derivative compounds that are no more toxic than the initial compound, Malathion 7.

Malathion-degrading bacteria produce catabolic enzymes-malathion carboxyl esterase and malathion dicarboxy latoxy reductase which are able to convert malathionic compounds into thiophosphates and phosphates ${ }^{8}$.

Profenofos pesticides will be broken down by bacteria into mono metabolite compounds and divalent acids through the enzymatic activity of oxidative desulfurization carboxylesterase ${ }^{6} 9$ and demethylation processes in mineralization mechanisms that cause minor routes of metabolism, including oxidation, reduction of sulfur and methyl. ${ }^{10}$. The result of enzymatic degradation by consortium bacteria is able to degardate Profenofos into simpler compounds, namely 4-Bromo-2-chlorophenol and 1-phenyl3-hydroxy-1, 2,4-triazole ${ }^{11}$

This article discusses critical areas regarding the degradation of Malathion and Profenophos residues contained in the water and sediments of the Rawa Pening lake by a consortium of indigenous bacteria Exiquobacterium profundum - Oceanobacillus iheyenis which are expected to produce simpler and non-toxic final compounds.

\section{MATERIAL AND METHODS}

Genomic DNA (Promega) Wizard Extraction Kit: EDTA, Lytic enzyme, nuclei lysis solution, RNAase solution, protein precipitation solution, DNA rehydration solution. Bact-FI primer. 5'AGAGTT TGATCMTGGCTCAG3 '/ UniB1.5'GGTTACSTTGTTACGACTT3' (Eurogentec AIT), agarose (Vivantis), ethanol 70\%, Ethidium bromide, isopropanol, loading dye (Vivantis), marker (Vivantis), and $\mathrm{HgCl}_{2}$. Sediment from Rawa Pening Lake, Profenofos and Malathion Pro Analisys (PA), Sigma Aldrich Laborochemikallen $\mathrm{GmbH}$, Malathion Pestanal Bath SEBC132XV, Profenofos pestanal Bath SZBC132XV, Malathon 96\% and Profenofos Curacron 500 EC

Microbial Identification based on 16S-rRNA Gene Analysis

Bacterial identification was carried out using the 16S-rRNA gene analysis method which included DNA extraction, DNA amplification, purification of DNA amplification results, DNA sequencing, and subsequent construction of phylogenetic trees to obtain genetic diversity.

\section{DNA extraction}

DNA extraction using the Chelex $100 \mathrm{Kit}$. Bacterial cells that have been grown for 24 hours are put into a $1.5 \mathrm{ml}$ Eppendorf tube containing $100 \mu \mathrm{l}$ of aquadest, then add $0.5 \%$ saponins and let stand for 24 hours at $4{ }^{\circ} \mathrm{C}$. The samples were centrifuged at $12,000 \mathrm{rpm}$ for 10 minutes, the supernatant from the centrifuge was discarded. A total of $1 \mathrm{ml}$ of Phosphate Buffer Saline (PBS 
$1 \mathrm{x})$ was added to the Eppendorf tube, then centrifuged again at 12,000 rpm for 15 minutes, the supernatant was removed, $100 \mu \mathrm{l}$ aquadest and $50 \mu \mathrm{l}$ Chelex 100 were added to the tube. The samples were boiled for 10 minutes (samples were vortexed in the first 5 minutes), then centrifuged again at $12,000 \mathrm{rpm}$ for 10 minutes. The DNA containing the supernatant is transferred to a new Eppendorf tube which is ready for the DNA amplification process. ${ }^{12}$

\section{DNA amplification}

Amplification is a molecular marker using the 16s rDNA Polymerase Chain Reaction (PCR) method. The temperature treatment used in the DNA amplification process is initial denaturation at $95^{\circ} \mathrm{C}$ for 3 minutes, then 30 cycles (denaturation at $95^{\circ} \mathrm{C}$ for 1 minute, annealing process at $55^{\circ} \mathrm{C}$ for 1 minute and extension at $72^{\circ} \mathrm{C}$ for 1 minute ), then extension at $72{ }^{\circ} \mathrm{C}$ for 7 minutes ${ }^{13}$. The primers used for PCR 16S rDNA were universal primers for 27F bacteria (5'-AGAGTTTGATCMTGGCTCAG-3') and eubacteria specific primers 1492R (5'-TACGGYTACCTTGTTACGACTT- 3 ') ${ }^{14}$. The mixture of materials used were Promega kit ( $25 \mu \mathrm{l})$ primer $27^{\circ} \mathrm{F}(2.5 \mu \mathrm{l})$, primer $1492 \mathrm{R}(2.5 \mu \mathrm{l})$, DNA template $(2.5 \mu \mathrm{l})$ and aquabides $(17.5 \mu \mathrm{l})$ so that total volume $50 \mu \mathrm{l}$. The ingredients were mixed in a 0.2 ml PCR tube. ${ }^{15}$

\section{Visualization of DNA Amplification Results}

Visualization of the results of DNA amplification was carried out through electrophoresis by inserting $5 \mu \mathrm{l}$ of PCR products into $1 \%$ agarose gel wells. Making $1 \%$ agarose gel by dissolving 1 gram of agarose in $100 \mathrm{ml}$ of TAE $1 x$ buffer solution, then heating it in an oven until homogeneous. A total of $5.33 \mu$ l Ethidium Bromide was put into the gel solution and shaken so that it was homogeneous. The gel solution is poured into a comb-shaped mold that is placed in an upright position so that it passes through the comb to the desired thickness. Then the gel was allowed to stand for a while until it hardened, then the gel was immersed in a 1X TAE buffer solution, the gel was electrophoresed with a voltage of $100 \mathrm{~V}$ for \pm 30 minutes. The amplified DNA bands were observed using the Gel Documentation tool. ${ }^{16}$ Purification of DNA Amplification Result

Purification was carried out to obtain pure DNA from PCR 165 rDNA amplification. The PCR results were centrifuged at a speed of 12,000 rpm for 7 minutes. The supernatant was removed using a micropipette until the DNA was completely pure. A total of $50 \mu \mathrm{l}$ of sterile aquadest was added to the DNA pellet and the results of the pure DNA were sequenced to determine the sequence of DNA bases. ${ }^{17}$

\section{DNA sequencing}

Sequencing was carried out according to the PCR sequencing cycle using Big Dye Terminator v.3.1. The formula for sequencing PCR reactions are $2 \mu \mathrm{l}$ big dye, $2 \mu \mathrm{l} 10 \mathrm{x}$ buffer, $4 \mu \mathrm{I}$ DNA template, $1 \mu \mathrm{l}$ primer with a concentration of $3.2 \mathrm{pmol}, \mathrm{ddH} 2 \mathrm{O}$ to a final volume of $10 \mu \mathrm{l}$. DNA amplification carried out by cycles were initial denaturation $\left(96^{\circ} \mathrm{C}\right.$ for 2 minutes), denaturation $\left(96^{\circ} \mathrm{C}\right.$ for 10 seconds); annealing $\left(50{ }^{\circ} \mathrm{C}\right.$ for 5 seconds); and extension (60 ${ }^{\circ} \mathrm{C}$ for 4 minutes) by 25 cycles. PCR results were purified and sequenced using $27 \mathrm{~F}$ primer. The sequences were analyzed automatically $(A B I$ 3130XL, Applied Biosystem). ${ }^{18}$

\section{Phylogenetic Tree Construction}

The pesticide-degrading bacteria that had successfully amplified their 16S rRNA gene could be seen from their relationship with other prokaryotes in the database based on their 16S-rRNA gene sequences. The results of partial sequences are edited using the Bioedit program. After obtaining data on the results of nucleotide sequence contigs, the homology will be compared with other prokaryotes in the Gene Bank database. ${ }^{19}$ Cluster analysis was carried out using a database from the RDP website (Ribosomal Database Project) with the website (http://www.rdp.com). while making phylogenetic trees using the MEGA 5 program ${ }^{20}$

Biodegradation Test of Malathion and Profenofos The quantitative data analysis was carried out by determining the levels of Malathion and Profenofos which could be obtained based on the area of the chromatogram produced on Gas chromatography-Mass Spectrometry (GCMS). ${ }^{21}$ The analysis was performed using a Gas Chromatography-Mass Spectrometry (GS-MS) instrument. The GS-MS conditions at the time of the study were injector temperature $250^{\circ} \mathrm{C}$, oven temperature $80^{\circ} \mathrm{C}$, column temperature $280^{\circ} \mathrm{C}$, detector temperature $250{ }^{\circ} \mathrm{C}$, helium gas flow rate $1 \mathrm{ml} / \mathrm{min}$, constant rate, sample constant rate 1 /| splitless, standard mix 1 / 100 ppm..$^{22}$ To determine the degradation results of the 
specimens that had been refused were analyzed using GC MS at 0 hours, 96 hours and 192 hours observations.

\section{RESULTS AND DISCUSSION Identification of indigenous bacteria}

Molecular genetic identification of indigenous bacteria by using genomic-DNA isolation as a template, then the results of genomic-DNA isolation are shown based on the DNA-bands resulting from the 16S-rRNA gene amplification electrophoresis process, shown in the following figure (Fig. 1):

The species identification by polymerase chain reaction technology (PCR product) using gene-16S rDNA / 16S rRNA (PCR-amplified 16S rRNA) of bacterial species, was carried out using agarose gel electrophoresis method ${ }^{23}$. The DNA fragments with a size of 50-20,000 bp are the best sizes that agarose gel can separate ${ }^{24}$ Analysis using the 16S rDNA/16S rRNA gene has been carried out experimentally in the laboratory because the $16 \mathrm{~S}$ rDNA/16 rRNA gene is universal and is part of the ribosomal structural RNA which plays an important role in protein synthesis. Therefore the 16 rRNA gene is always present in prokaryotic organisms, is immortal, and almost never is transferred horizontally. This makes the 16S rRNA gene ideal for the reconstruction of the phylogenetic tree and the identification of prokaryotic organisms 25

The isolation process of the tested bacterial genome with the code RPL1 and RPL5 was marked by the formation of one band for each genome of the tested bacteria after being observed using Ultra Violete Transluminator, then it was described by the 16S rRNA gene coding band $1.5 \mathrm{~kb}$, then compared with a Marker (1 $\mathrm{kb}$ DNA ladder). The results of 16 rRNA DNA amplification were sequenced to obtain the nucleotide sequence and analyzed for similarities using the Gen Bank with the BLAST-N (Basic Local Alignment Search Toll-Nucleotode) program so that the homology and species of bacteria tested could be determined. ${ }^{26}$, to determine the phylogeny relationship / relationship with other organisms, the 16S rDNA sequencing results of RPL1 and RPL5 isolates were compared with 16S rDNA sequence data from several species obtained from the data bank. The $16 \mathrm{~S}$ rDNA sequence data was then synchronized with the ClustalX ver 2.0



Fig. 1. The Results from the Gel Electrophoresis process - 16S-rRNA Amplification. (M) Marker; (1) Bacteria Identification Code $=$ RPL1 and (2) Bacteria Identification Code $=$ RPL5

Table 1. Sequencing results (primary forward and reverse)

\begin{tabular}{llllll}
\hline No & Code & Nucleotide base (bp) & Species name & Homology & No accession \\
\hline 1 & RPL 1 & 1071 & Oceanobacillus iheyensis & $87 \%$ & LC10790 \\
2 & RPL 5 & 1238 & Exuquobacterium profundum & $99 \%$ & LC19791 \\
\hline
\end{tabular}


program $^{27}$ The next process is the creation of a phylogenetic tree using the MEGA version 5.03 program with the Neighbor-Joining Tree statistical method, 1000 bootstrap level $p$-distance models ${ }^{28}$ The PCR results of the $16 \mathrm{~S}$ rDNA gene were shown with a single band on the gel electrophoresis with a size of about $1500 \mathrm{bp}$.

The results of sequencing using forward and reverse primers to determine the sequence of bacterial nucleotide bases are as follows: (Table 1, fig 2 and fig 3)

Results of 16S-rRNA Gene Sequence of RPL1 Bacterial GGGGTATTGCATCATAATGCAGTC GAGCGCAGGAAGCTATCTGATCCTCTTTTAG AGGTGACGATAATGGAATGAGCGGCGGACGG GTGAGTAACACGTAGGCAACCTGCCTGTAAGAC TGGGATAACTCGTGGAAACG CGAG CTAATA CCGGATAACACTTTTCATCTCCTGATGAGAAGTTG AAAGGCGGCTTTTGCTGTCACTTACAGATG GGCCTGCGGCGCATTAGCTAGTTGGTAAGG TAATG G C T TA C CAAG G C G A C GATG C G TAGCCGACCTGAGAGGGTGATCGGCCACACTG GGACTGAGACACGGCCCAGACTCCTACGGGAG GCAGCAGTAGGGAATCTTCCGCAATGGAC GAAAGTCTGACGGAGCAACGCCGCGTGAGTGA TGAAGGTTTTCGGATCGTAAAACTCTGTTGTTA
GGGAAGAACAAGTGCCATAGTAACT ATGGCA CCTTG ACGGTACCTAACCAGAAAGCCACGGCTAACTAC GTGCCAGCAGCCGCGGTAATACGTAGGTG GCAAGC GTTGTCCGGAATTATTGC GCGTAAAGCGCTCGC AGGCGGTTCTTTAAGTCTGATGTGAAATCT TACGGCTCAACCGTAAACGTGCATTGGAAA CTGGGGAACTTGAGTGCAGAAGAGGAGA GTGCAATTCCACGTGTAGCGGTGAAATGC GTATAGATGTGGAGGAACACCAGTGGCGAAC GCGACTCTCTGG TCTGTAACTGACGCTGAGT AGCCAAGCGTCGGGAGCGACAGGATTAGATACC CTGGTAG CCCCTG CCGTAG ACGATGAG CGC TAGTCGTCAGGGGTTTCCGCCCCTTATGCTGAAG TTACTCATTAAGCACTCCACCTGTGACGTCAGA CGCAAGCATCAACTCAAAGGATTTACGCGGAC CA C T CAAG CG ATG AT C A CTCGTTTAAT TACAGCACCGCGAGAACTTACCAGGCTTGGATT CCTCTGAACATCTAAAATAG CCTTTCCTT CAGGGAAGAGTTCTCCCGACAAAGATTTTTCAA CCCANACCTAAATTTCAGTAAGCCCGCACGA AGAAATCTTGA

Results of 16S-rRNA Gene Sequence of RPL-5 Bacterial Samples CAATTGCG CGGCTATAATGCAGTCGAGCGCAGGAAACCG TCTGAACCCTTCGGGGGGACGACGGCGGA ATGAGCGGGGGACGGGTGAGTAAC



Fig. 2. Exiguobacterium profundum gene for $16 \mathrm{~S}$ rRNA, partial sequence, strain: RP-L-5 1,238 bp linear DNA GenBank: LC019791.1, species, firmicutes

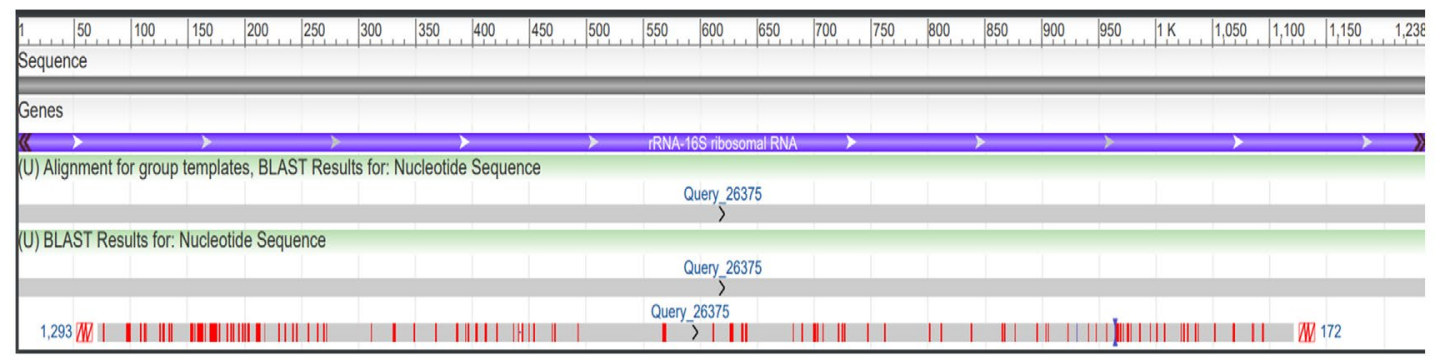

Fig. 3. Oceanobacillus iheyensis gene for $16 \mathrm{~S}$ rRNA, partial sequence, strain: RP- L-1 1,071 bp linear DNA. species, firmicutes 
ACGTAAAGAACCTGCCCATAGGTCTGGGATAAC CACAAGAAATCC GGGCTAATACCGGATGTGTCAT CGGACCGCATGGTCCGCTGATGAAAGGGGCTCCG GCGTCTCCCATGGATGGCTTTGCGGTGCATTAGC TAGGTGGTGGGGTAAAGGCCCACCAAGGCG ACGATGCATAGCCCAGCTGAGAGGGTGATCGGCCAC ACTGGGACTGAGACACGGGCCAGACTCC TACG G G A G G G G CA GTA G G A ATCT T CCCCAATGGACGAAAGTCTGATGGAGCAACG
CCGCGTGAACGATGAAAGCTTTCGGGGCGTAA AGTTCTGTTGTAAGGGAAGAACAAGTGCCGCAC G CAATG G CG G CG C C T T G A C G G TAC C T TGCGAGAAAGCCACGGCTAACTACA TGCCAGCAGCCGCGGTAATACGTAGG TGGCAAGCGTTG TCCG GAATTATTGGG CGTAAAGCGCGCGCAGGCGGCCTCTTAAGT CTGATGTGAAAG C C C CGGCTCAACC G G G A A G GCCATTGGAAACTGGGA

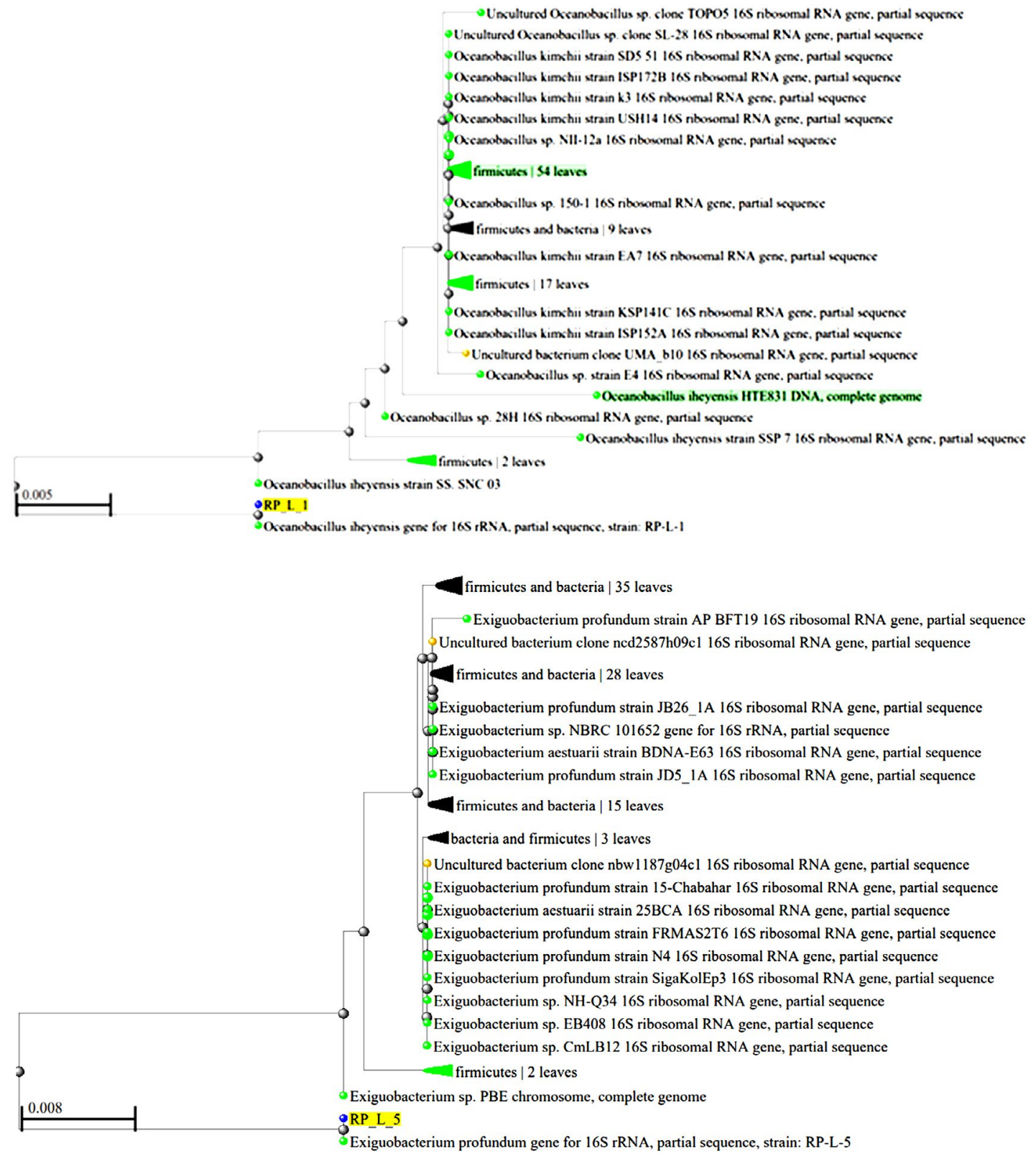




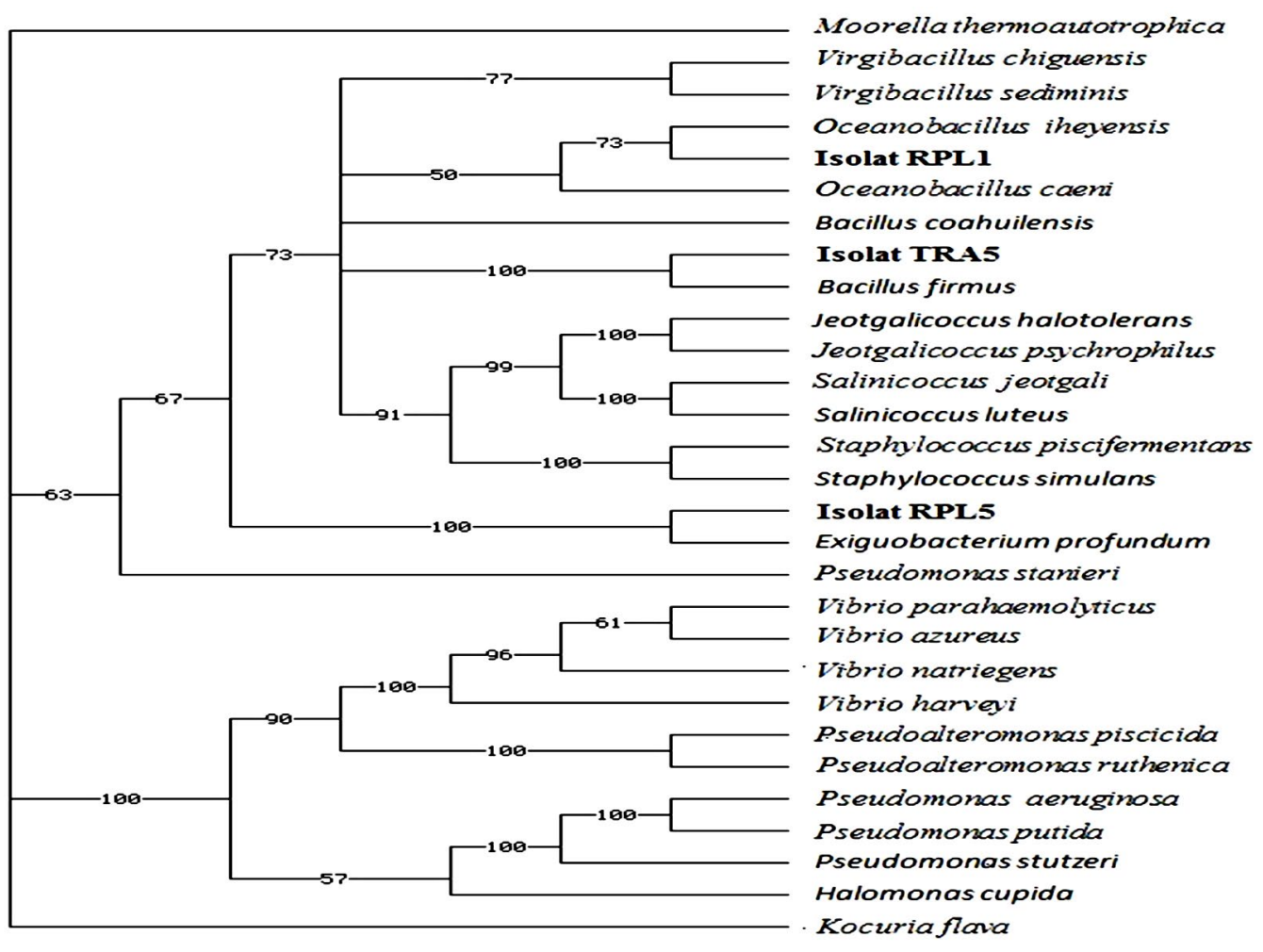

Fig. 4. Phylogenetic tree reconstruction results

CompName:Malathion E50 SS Butanedioic acid. [(dimethoxyphosphinothioyl)thio]. diethyl ester (CAS) SS TM-4049 SS ENT 17.034 SS SF 60 SS Malathic

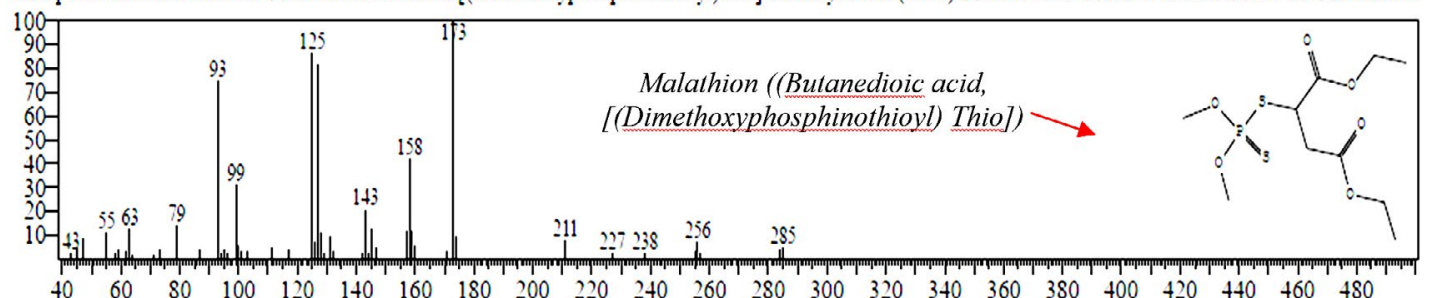

Fig. 5. The chromatogram of the chemical compound Malathion $\left(\mathrm{C}_{10} \mathrm{H}_{19} \mathrm{O}_{6} \mathrm{PS}\right.$ or Butanedioic acid, ((dimethoxyphosphinothioyl) thio) -, monoethyl ester

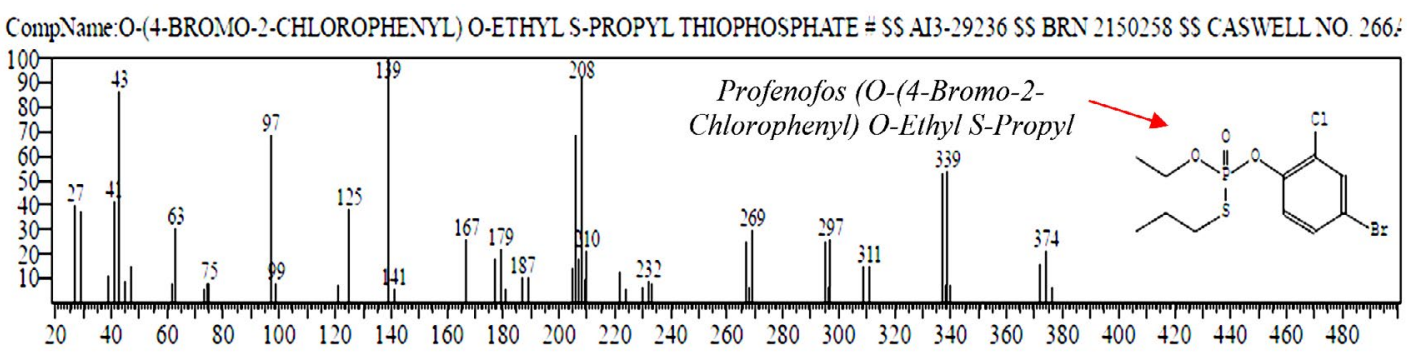

Fig. 6. Chromatogram and chemical structure of Profenofos (O- (4-Bromo-2-Chlorophenyl) O- Ethyl S- Propyl Thiophosphate)) 
G GCTTGAGTATATGA GA A A GAGTGGA AT T C CA C G T G TA G C G G T G A A T G C G TA C A G ATG T G A A G G A C A CCCTTGTCGAAAGCGACTCTTTGGCCTATA TCTGACGCTGAGGCGCGAAAACGTGGG GAGCAACACGATTAGATACCCTGGTAGTC C A C G C CG TA A A CGATGAGAG CTAA GTGTTGGAGGGTTCCGCCCTTTGTGCT CAGCTAAGCATTAACACTCCCCTGGGGA GACAGTCGCAGGCTCAACTCAAGGATTG ACGGGACCCCACACCAGTGGAGCATGTGGTT TATTTGAGCACACGGAAAACTTTCCACTCTTG AATCCCCTGACCGGAAAAAATGTACCTTCC CTCTGGGGCAGGGTGACAAGTGTGGATG GTTGCGTCA G CCCCGTCCGAGAGATG C G TTAATCCCCAACAAGGCAACCTTGTCTTTTTTGC ACATTCGTTGGCCCCCTAGGAAATGCCG TGACA A C C G A A G A G G G G ATA A CCAAATTCATGCCCTTAAAGTGGGTACACGT GTCAATGGAGGGCAAGGGACCCAAC CCCAGTGGAC CATCCCAAACGTTTCNTTGGATGGGGGGCACC C C C G TA G A C C G A A T C T G G C G G T T G TATACATGCAGTCGAGCGGACAGATGGGA
GCTTGCTCCCTGAAGTCAGCGGCGGACGGGT GAGTAACACGTGGGCAACCTGCCTGTA A GACTGG GATAACTCCGGGAAACCGGG GCTAATACCGGATAATTCTTTCCCTCACATGAGGGA AAGCTGAAAGATGGTTTCGGCTATCACTT ACAGATGGGCCCGCGGCGCATTAGCTAGT TGGTGAGGTAACGGCTCACCAAGGCAAC GATGCGTAGCCGACCTGAGAGGGTGA TCGGCCACACTGGGACTGAGACACG G CCCAGACTCCTACGGGAGGCAGCAGTAGG GAATCTTCCG CAATGGACGAAAGTCTGACGGAGCA A C G C C G C G T G A G T G A T G A A G G T TTTCGGATCGTAAAACTCTGTTGTTAG g GA A GACA A TACCGGAGTAA CTGCCGGTACCTTGACGGTACCTAACCA gAAAGCCACGgCTAACTACGTGCCAgCA GCCGCGGTAATA CGTAGGTGGCAAGCGTTGT CCGGAATTATTGGGCGTAAAGCGCGCGCA G G CG TT TCCTTAAG T C TGATGTGAA A GCCCCCG G C T C A A C C G G G A GGGTCATTGGAAACTGGGGACTTGAGT GCAGAAGAGAAGAGTGGAATTCCACGTGTA G C G G T G A A T G C G TA G A G ATG T G G

Table 2. Chemical compounds from the biodegradation of the consortium bacteria (observation $\mathrm{t}=0$ hours)

\begin{tabular}{llllll}
\hline Peak & R.Time & Area & Area\% & Height & Name \\
\hline 1 & 4.034 & 163.635 & 6,7 & 21025 & (R,S)-2-Butanol, (3R)-3-[(Benzyloxycarbonyl)Amino]- \\
2 & 4.240 & 57.279 & 2,4 & 12654 & T-Butyl (R)-3-(Benzyloxy)-Butanoate \\
3 & 7.957 & 59.397 & 2,4 & 14450 & 4,6-Dimethyl-4-Hydroxyhept-5-Enoic Acid \\
4 & 13.113 & 98.397 & 4,0 & 39793 & Pentadecanenitrile(CAS) \\
5 & 17.833 & 427.673 & 17,6 & 141327 & Hexadecanenitrile(CAS) \\
6 & 18.384 & 171.142 & 7,0 & 61700 & Hexadecanoic Acid,Methyl Ester(CAS) \\
7 & 19.675 & 179.194 & 7,4 & 61739 & Malathion E50 \\
8 & 21.927 & 145.766 & 6,0 & 45806 & 9-Octadecenal,(Z)-(CAS) \\
9 & 22.345 & 85.071 & 3,5 & 30227 & 9-Octadecenoic Acid (Z)-,Methyl Ester(CAS) \\
10 & 22.481 & 126.591 & 5,2 & 42298 & Hexadecanenitrile(CAS) \\
11 & 22.958 & 65.369 & 2,7 & 21510 & Heptadecanoic Acid,16-Methyl-,Methyl Ester(CAS) \\
12 & 23.914 & 87.158 & 3,6 & 43370 & Hexadecanamide(CAS) \\
13 & 23.957 & 168.200 & 6,9 & 72947 & O-(4-Bromo-2-Chlorophenyl)O-Ethyl \\
& & & & & S-Propyl Thiophosphate \# \\
14 & 25.481 & 79.450 & 3,3 & 27975 & 9-Octadecenamide(CAS) \\
15 & 25.635 & 147.922 & 6,1 & 29660 & 1,1,3,3,5,5,7,7,9,9,11,11,13,13-Tetradecamethylheptasiloxane \\
16 & 26.930 & 91.252 & 3,8 & 17443 & 1-Piperazinepropanamide, N-(4-Fluorophenyl)-4-Methyl- \\
17 & 27.164 & 60.743 & 2,5 & 17767 & 3-Octadecene-1,2-Diol(CAS) \\
18 & 27.258 & 58.346 & 2,4 & 20271 & 14.Alpha-Cheilanth-12-Enic Methyl Ester \\
19 & 28.801 & 82.966 & 3,4 & 15704 & Silicone Grease,Siliconfett \\
20 & 29.705 & 77.285 & 3,2 & 19635 & Silicone Grease,Siliconfett \\
& & 2432836 & 100 & 757301 &
\end{tabular}




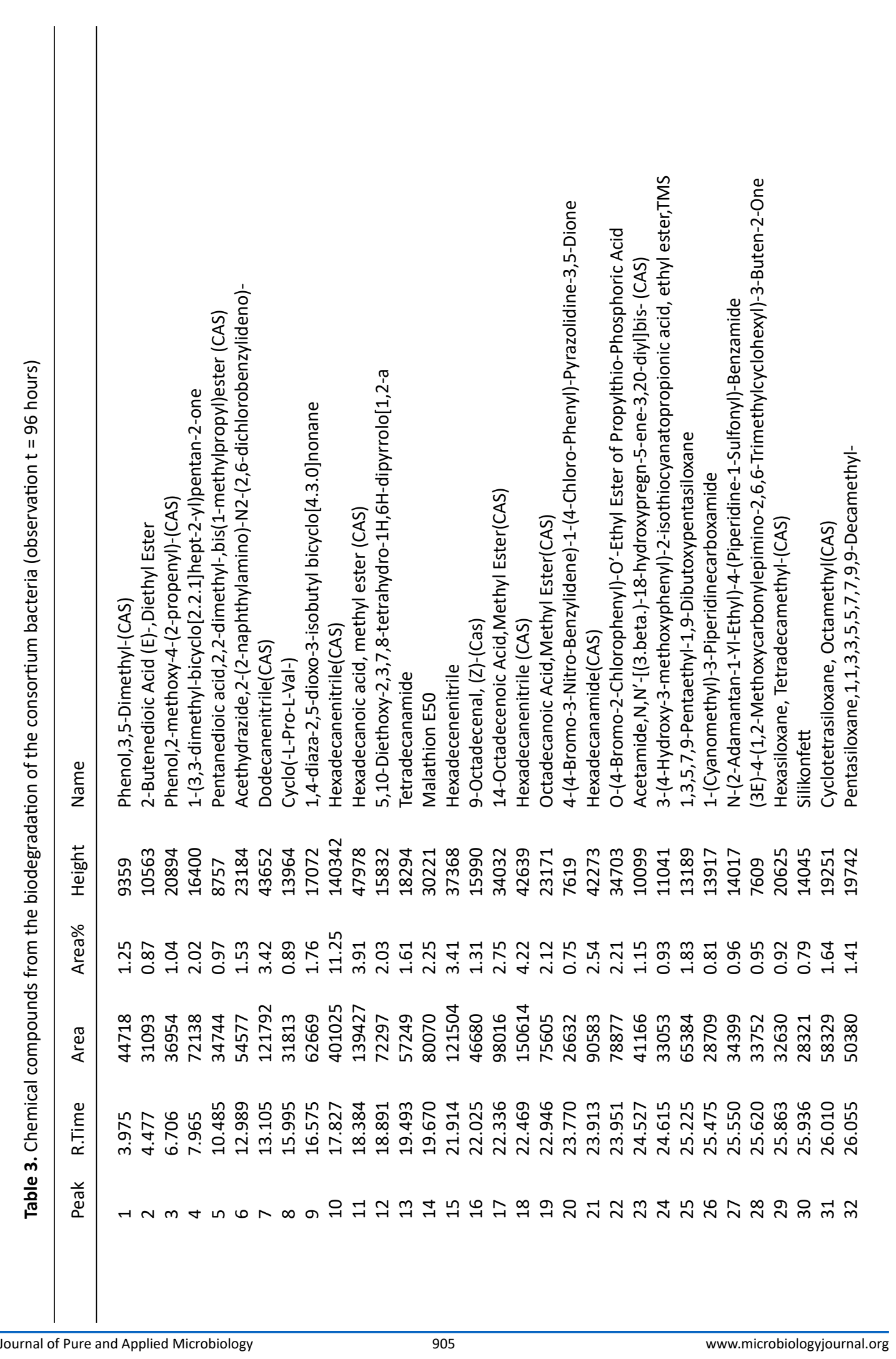




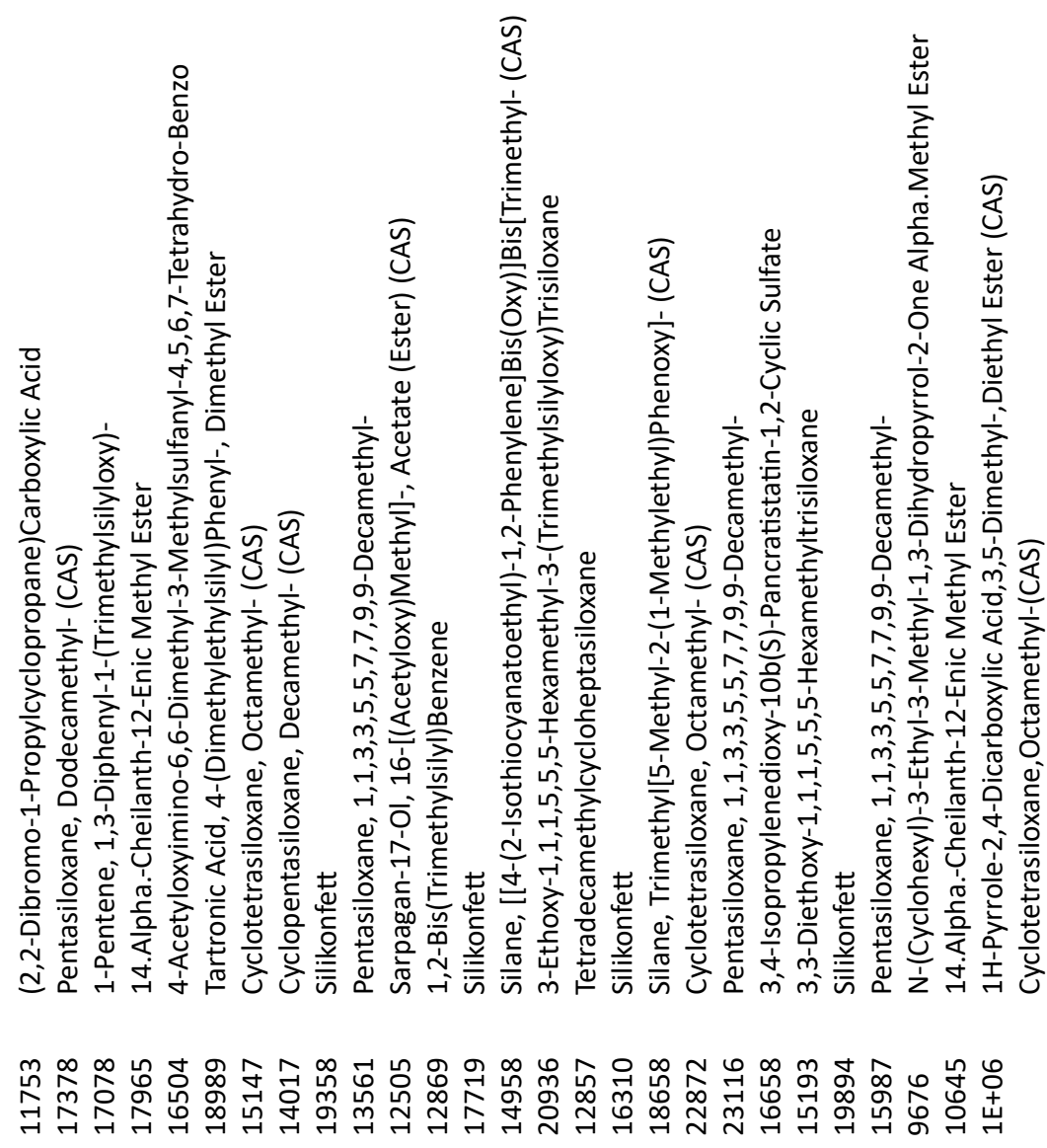

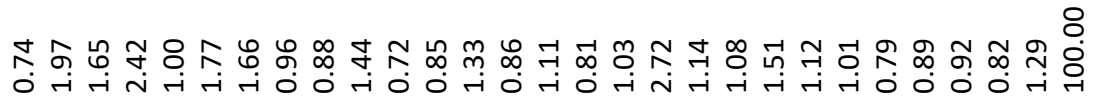



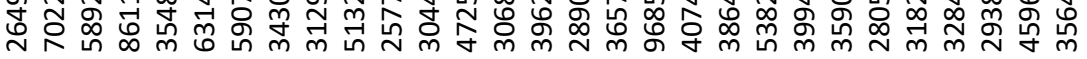

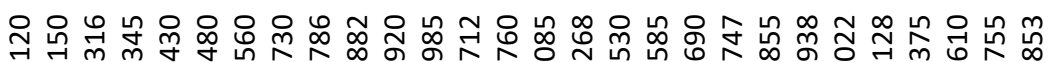

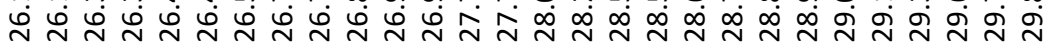

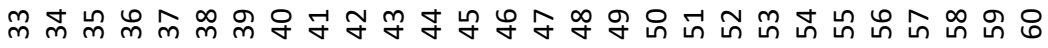


AGGAACACCAGTGGCGAAGGCGACTCTTTGGTC TGTAACTGACGCTGAGGCGCGAAAGCGTGGGG AGCAAACAGGATTAGATACCCTGGTAGTCC ACGCCGTAAACGATGAGTGCTA AGTGT TAGAGGGTTTCCGCCCTTTAGTGCTGCAGCAAA C G CATTAA G CA C T C C G C C T G G G G A T ACGGCCGCAAGGCTGAAACTCAAAGGAATT GACGGGGGCCCGCACAAGCGGTGGAGCAT GTGGTTTAATTCGAAGCAAC GCGAAGAACCTTACC AGGTCTTGACATCTCCTGACAACCCTAGAGATAGG GCGTTCCCCTTCGGGGGA CAGGATG ACAGGTGGTG CATGGTTGTC GTCAGCTCGTGTCGTGAGATGTTGGGT
TAAGTCCCGCAACGAGCGC AAC CCTTGAT CTTAGTT GCCAGCATTCAGTTGGGCACTCTAAGGTGACT GCCGGTGACAAACCGGAAGGAGGTGGG GGATGACGGTCAAATCATCATG GCCCCTTA AGGACCTGGGGCTAACNCACGTGCTACAATGGGA T G G G A A C A A A G G G G T T C G A A G A C C C GCAAGGTTAANCGGAATCCCCATAAAACATTT TTCAAGTTCN GAATTG CAGGGTTGAAACTCTCC TTGTTTGAAACCCGGATT

Based on the phylogenetic tree analysis, the test bacterial isolate with code RPL1 has the closest relationship with the Oceanobacillus

Hit $=1$ Entry.434747 Library:Wiler9.lib

SI:79 Formula:C10H1906PS2 CAS:121-75-5 MolWeight330 RerIndex:0

CompName:Malathion E50 SS Butanedioic acid. [(dimethoxyphosphinothioyl)thio]- diethyl ester (CAS) SS TM-4049 SS ENT 17.034 SS SF 60 SS Malathi

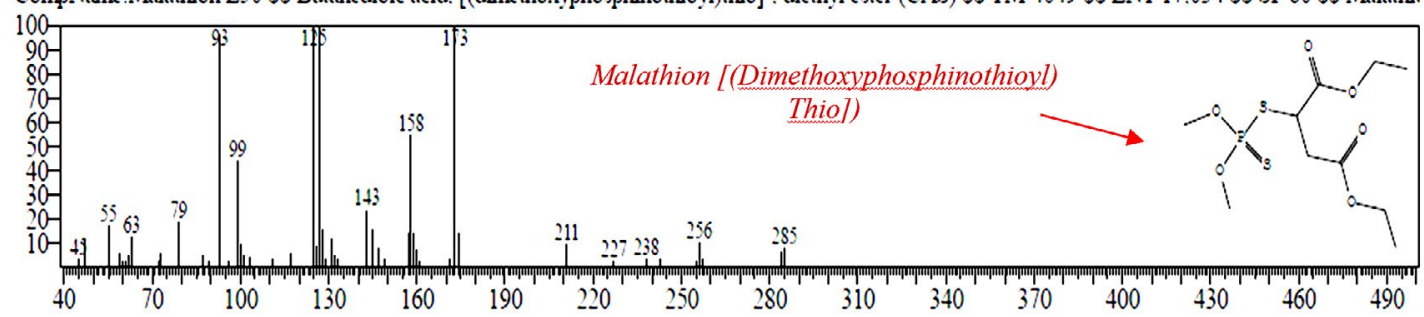

Fig. 7. The chromatogram and chemical structure of Butanedioic Acid Malathion [(Dimethoxyphosphinothioyl) Thio] at observation $\mathrm{t}=96$ hours

SI:60 Fonmula:C11H15BrC103PS CAS:41198-08-7 MolWeight:372 RetIndex:0

Complame:O-(4-BROMO-2-CHLOROPHENYL)-0'-ETHYLESTER OF PROPYLTHO-PHOSPHORIC ACID S\$ Profenofos \$S Curacron S\$ Selecron \$

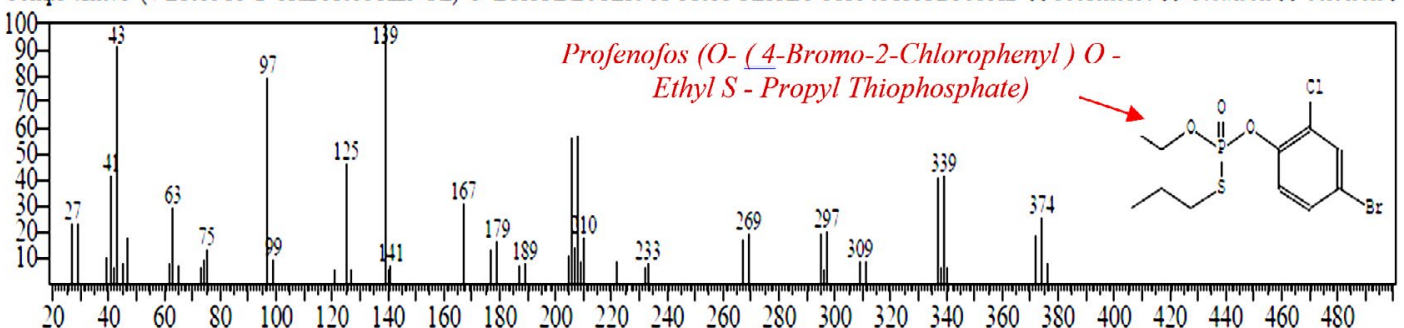

Fig. 8. The chromoatogram and chemical structure of Profenofos[O-(4-Bromo-2-Chlorophenyl) -O'-Ethyl Ester Of Propylthio-Phosphoric Acid] at observation $t=96$ hours

Sl:32 Formula:Cl6H9BrCIN304 CAS:0-00-0 MolWeight:421 Retlndex:0 CompName-4-4-BROMO-3-NITRO-BENZYL.IDENE)- - - -4-CHLORO-PHENYL).PYRAZOLIIDINE-3,5-DIONE SS 4-(4-BROMO-3-NITROBENZYLLID

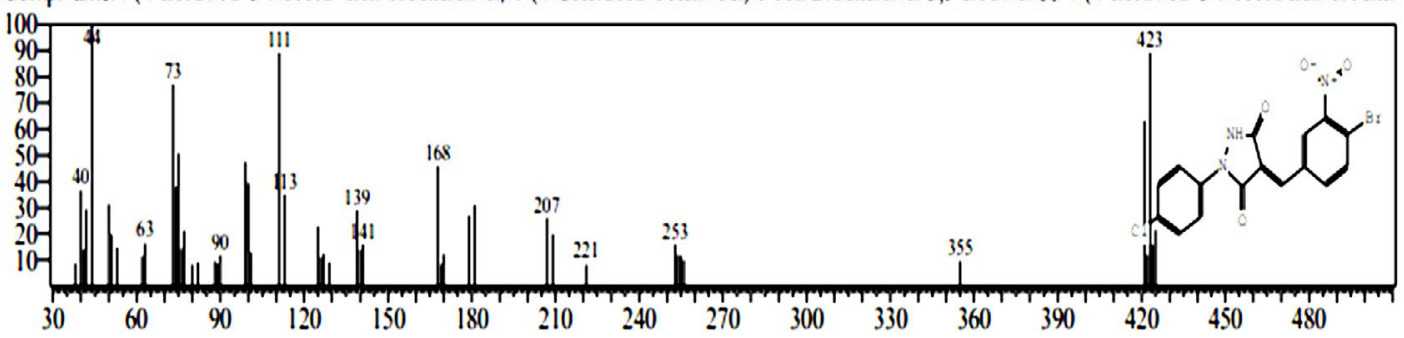

Fig. 9. Chemical compounds (4 - Bromo - 3 -Nitro - Benzylidene) -1- (4-Chloro - Phenyl) -Pyrazolidine-3,5-dione 
iheyenis bacteria with a maximum similarity rate of $87 \%$, while the tested bacterial isolates with code RPL5 had the closest relationship with Exiquobacterium profundum with a maximum similarity level of 99\%. as follows (Fig 4)

Biodegradation of Profenofos and Malathion by indigenous bacterial consortium

Oceanobacillus iheyenis and

Exiquobacterium profundum are indigenous bacteria isolated from the Rawa Pening lake. Both of these bacteria have the ability to degrade against Malathion and profenofos, therefore these bacteria are used as consortium bacteria for research on the biodegradation process of Malathion and Profenofos. The results of Isworo, Purwanto and Sabdono (2016) The results of the test of the degradation ability of selected bacteria in the form of a consortium showed a better ability than the degradation ability of a single isolate. The bacterial consortium Exuquobacterium profundum and Oceanobacillus iheyensis had the best degradation ability of $83.23 \%$ while the bacteria consortium Exuquobacterium profundum and bacillus formis had the best degradation ability with a value of $68.75 \%$ on the Profenofos substrate ${ }^{29}$. The detected biodegradation chemical compounds will be translated into a chromatogram that represents the compound being analyzed. Analysis of the test sample was carried out by observing the retention time and chemical structure of Malathion and Profenofos due to degradation from the bacterial consortium. ${ }^{30}$ Observations

Hitt:1 Entry:505369 Library:Wiley9.lib

Sl 60 Formula CIIHI5BrCIO3PS CAS 41198-08-7 MolWeight:372 Retindex:0

CompName:O-(4-BROMO-2-CHL.OROPHENYL)-O'-ETHYL ESTER OF PROPYLTHIO-PHOSPHORIC ACID \$\$ Profenofos \$S Curacron \$S Selecron \$

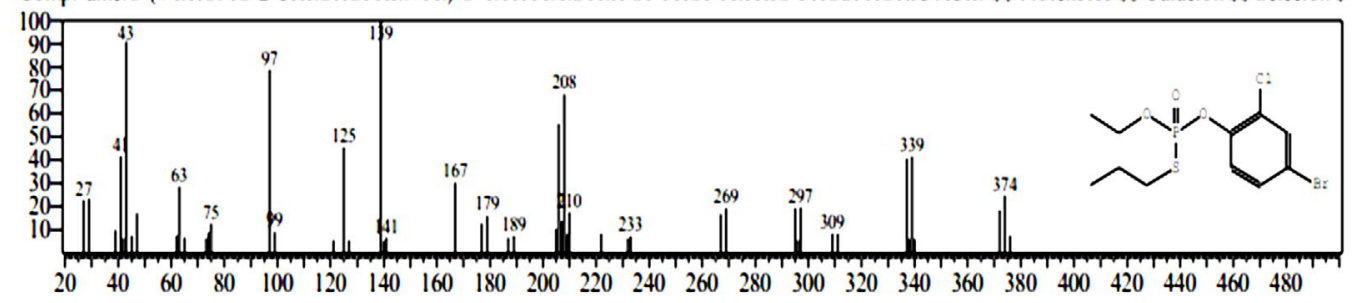

Fig. 10. The chemical compounds O-(4-Bromo-2-Chlorophenyl)-O'-Ethyl Ester of Propylthio-Phosphoric Acid

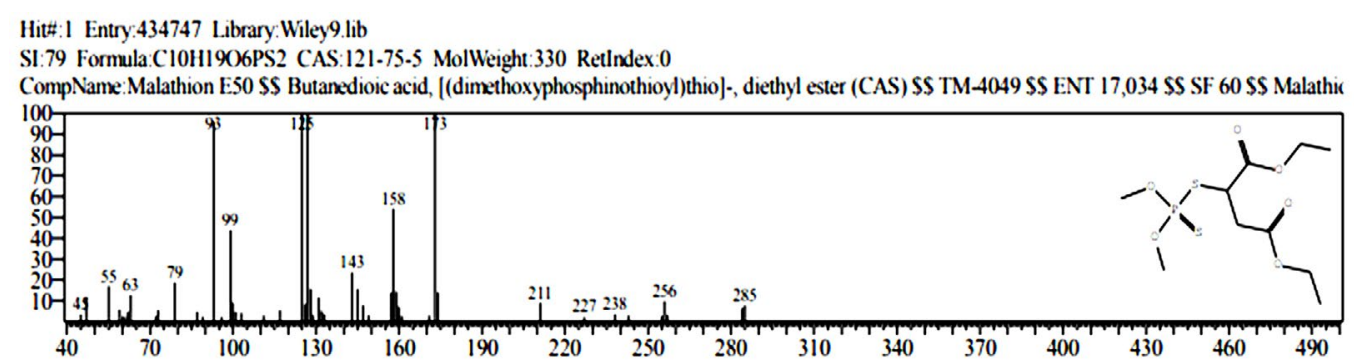

Fig. 11. Chemical compounds of Butanedioic Acid, [(Dimethyl Phosphinothioyl) Thio])

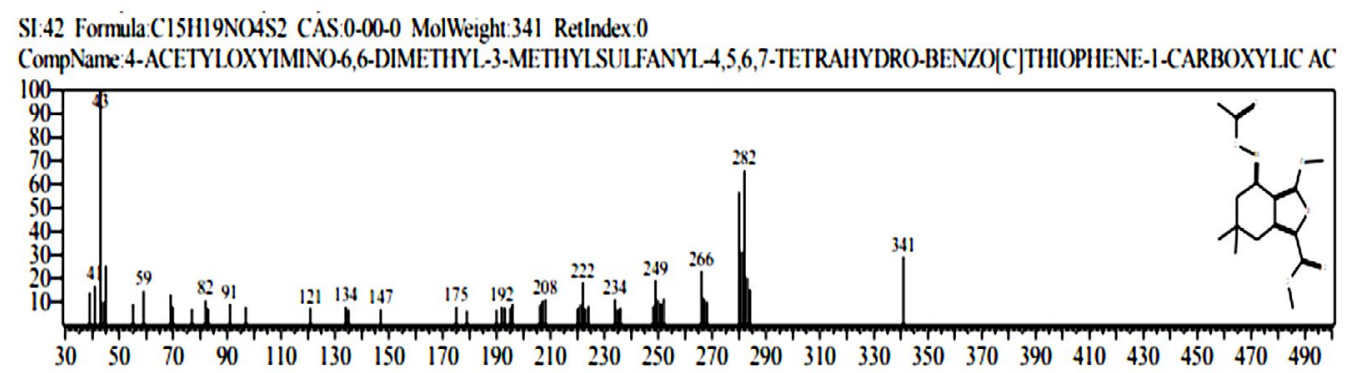

Fig. 12. The chemical compounds 4-Acetyloxyimino-6,6-Dimethyl-3-Methylsulfanyl - 4,5,6,7-Tetra hydro-Benzo [C] Thiophene-1-Carboxylic Acid 







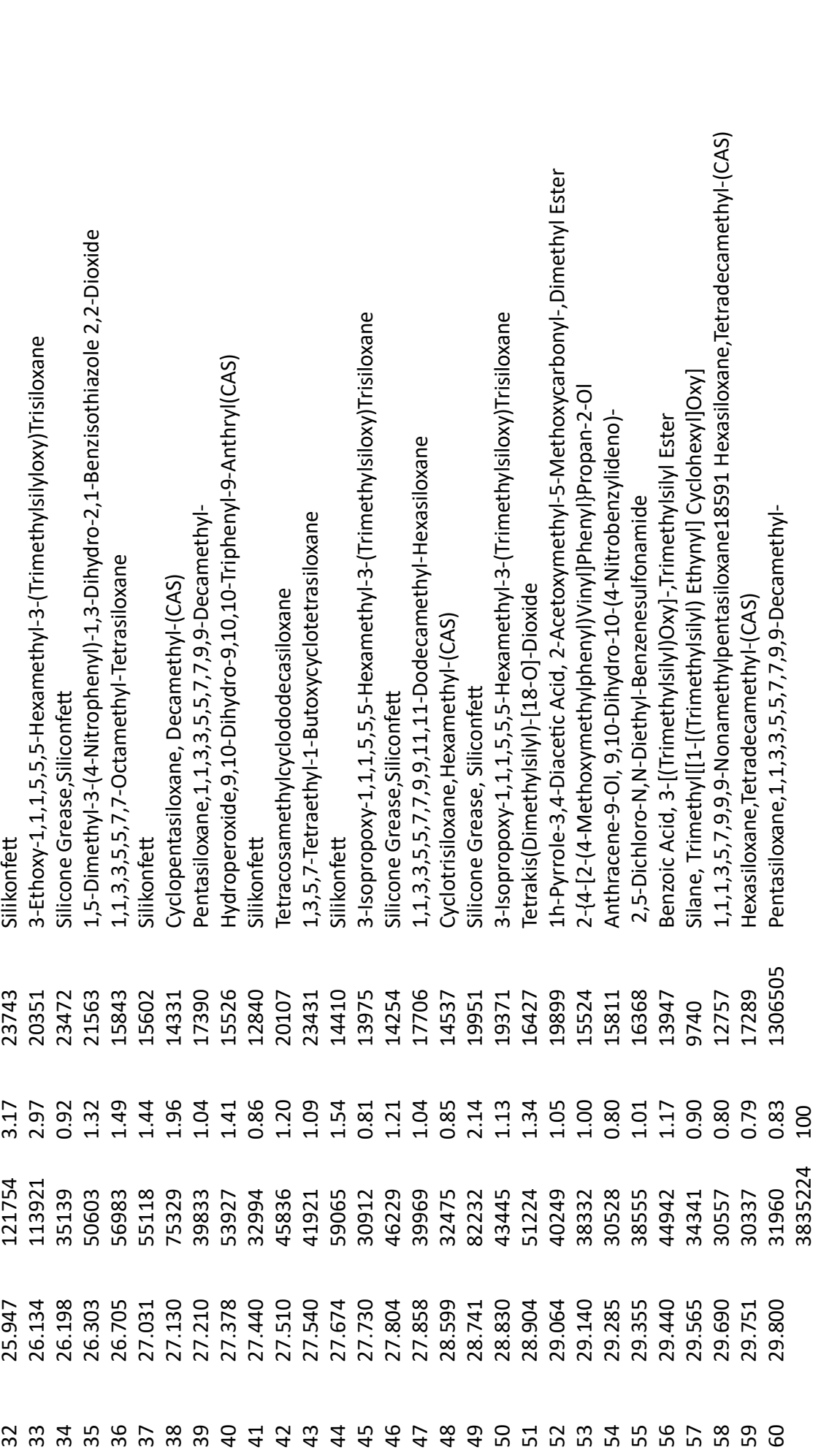


Hitł:1 Entry:229210 Library:Wiley9.lib

SI:90 Formula C16H3IN CAS:629-79-8 MolWeight 237 RetIndex:0

CompName:Hexadecanenitrile (CAS) \$\$ Palmitonitrile \$\$ Palmitic acid nitrile SS Palmitic acid, nitrile \$S N-HEXADECANONITRIL.E SS I-Cyanopentade

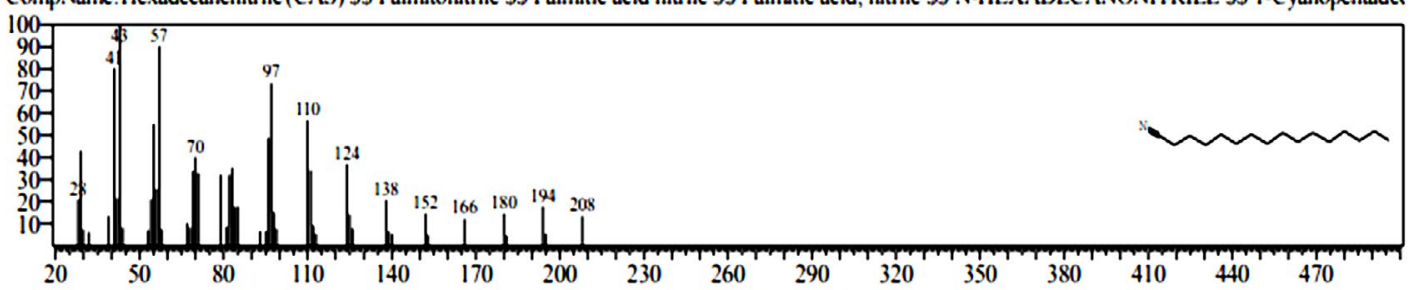

Fig. 13. The chromatogram of chemical compounds Hexadecanenitrile(CAS) Palmitonitrile, Palmitic acid nitrile, $N$-Hexadecanonitrile, 1-Cyanopentadecane

Hitł:I Entry. 434460 Library:Wiley9.lib

SI:39 Formula:C21H15NO3 CAS:148215-43-4 MolWeight:329 Retindex:0

CompName:Anthracene-9-ol, 9,10-dihydro-10-(4-nitrobenzylideno)- \$\$ 10-(4-Nitrobenzylidene)-9,10-dihydro-9-anthracenol SS 10-(4-NITROBENZYLDE

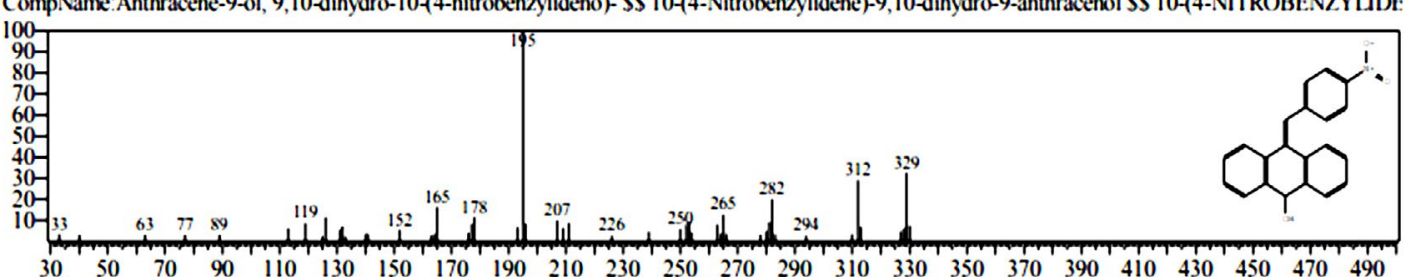

Fig. 14. Chromatogram of chemical compounds Anthracene -9-0I, 9,10-Dihydro-10- (4-Nitrobenzylideno) (Functional Group - Ol / Alcohol)



Fig. 15. The chromatogram of chemical compounds 2- \{4-[2-(4-Methoxymethylphenyl) vinyl] phenyl\} propan-2-ol (functional group -ol/alhohol)

Hit\#:I Entry 504579 Library:Wiley9lib

SI:70 Formula:C19H15CI2N3O CAS 0-00-0 MolWeight:371 RetIndex:0

CompName: Acethydrazide, 2-(2-naphthylamino)-N2-(2,6-dichlorobenzylideno)- $\$ S \mathrm{~N}-(\mathrm{E}-\mathrm{E})-(2,6-\mathrm{Dichlorophenyl)})$ methylidene)-2-(2-naphthylamino)acetohyc

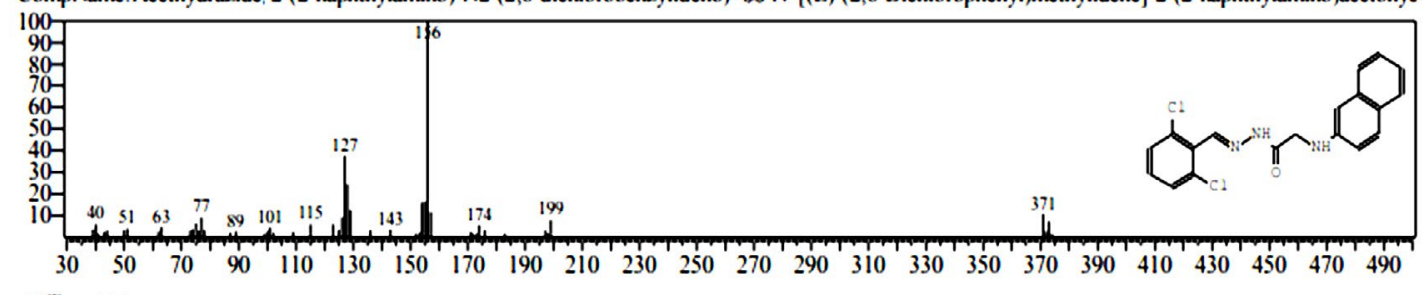

Fig. 16. The chromatogram of chemical compounds Acethydrazide compound, 2- (2-naphthylamino) - N2 - (2, 6 - dichloro benzylideno) 
and sampling were carried out at 0 hours, 96 hours, and 192 hours. The chromatogram of chemical compounds biodegradation of the bacterial consortium Exiquobacterium profundum - Oceanobacillus iheyenis at $\mathrm{T}=0$ hours then detected the malathion compound $\mathrm{C}_{10} \mathrm{H}_{19} \mathrm{O}_{6} \mathrm{PS}_{2}$ or Butanedioic acid, ((dimethoxyphosphinothioyl) thio) -, monoethyl esterer ${ }^{31}$, detected on peak 4 with real time $=19,675$, area $\%=7.37$, is follow : (fig 5)

While the cromatogram for the chemical compound Profenofos with the chemical formula $\mathrm{C}_{11} \mathrm{H}_{15} \mathrm{BrClO}_{3}$ PSO- (4-bromo-2-chlorophenyl) o-ethyl s-propyl thiophosphate ${ }^{32}$ was detected at peak 8 , real time $=23,957$, area $\%=6.91$, as follow : (fig 6)

The complete data on the chemical compounds resulting from degradation is explained based on observations on GC MS with the parameters Peak, Real-Time, Area\%, as follows (table 2):

In the observation time of $t=0$ hours that the tested Malathion and Profenofos compounds were still detected, this indicates that the Malathion and Profenofos compounds have not been completely degraded into simpler compounds.

The chromatogram data of chemical compounds biodegradation results from the bacterial consortium Exiquobacterium profundum-Oceanobacillus iheyenis at $\mathrm{T}=96$ hours observations, are completely shown in table 3 , which is the result of staging on GC MS with parameters peak, real-time, area\%, as follow :

Based on table 3, it shows that the compound Malathion [(Dimethoxyphosphinothioyl) Thio)] was detected at peak 14, real time $=19.675$, area $\%=2.25$ while Profenofos (O-(4-Bromo-2-Chlorophenyl)O-Ethyl S-Propyl Thiophosphate) detected at peak $=22$, real time $=23,951$ and area\% $=2.2$, as follows (Fig 7 and fig 8):

Also detected a chemical compound (4-Bromo-3-Nitro-Benzylidene) -1- (4-ChloroPhenyl) -Pyrazolidine-3,5-dione which is the result of degradation of the profenofos compound, at peak $=20$, real-time $=23,770$, area $\%=0.75$, as follows: (Fig 9)

Likewise the chemical compound O- (4-Bromo-2-Chlorophenyl) -O'-Ethyl Ester from Propylthio-Phosphoric Acid resulted from the enzymatic degradation of Profenofos by bacteria, this compound was detected based on a chromatogram at peak $=22$, real-time $=24.525$ and area $\%=2.21$, as follow : (Fig 10)

The chemical compound resulting from the degradation of Profenofos (Profenofos O- (4-Bromo-2-Chlorophenyl) O-Ethyl S-Propyl Thiophosphate) will become a compound of phosphorus and phosphate groups which are degradation compounds that are not toxic. ${ }^{33}$

In table 3 also detected compounds resulting from enzymatic malathion degradation by the bacterial consortium, is Chemical compounds of Malathion degraded into Butanedioic Acid, [(Dimethoxyphosphinothioyl) Thio]) detected at peak $=2$, real-time $=4,477$, area $\% .=0.87$ (fig 11)

The chemical compound Butanedioic Acid, [(Dimethoxyphosphinothioyl) Thio] -, Diethyl Ester is a synonym for Malathion Dicarboxylic Acid or Mercapto-O, O-Dimethyl Phosphorodithioate Succinic Acid which is the result of aerobic degradation of Malathion. Butanedioic Acid, [(Dimethoxyphosphinothioyl) Thio] -, Diethyl Ester will be degraded into a compound with this carboxylate group, namely 4-Acetyloxyimino-6,6Dimethyl-3-Methylsulfanyl-4,5,6,7-Tetra hydroBenzo [ C] Thiophene-1-Carboxylic Acid. the compound was detected at peak $=37$. real time $==26.430$, area $\%=1.00$, as follows: ${ }^{3435}$. (fig 12)

Based on these data, Malathion and Profenofos compounds have been degraded into simpler compounds, this can be compared with the decrease in peak values, real time and\% area of Malathion and Profenofos compounds. ${ }^{36}$

The chromatogram of chemical compounds degradation of Malathion and Profenofos by the bacterial consortium Exiquobacterium profundum-Oceanobacillus iheyenis at observation $t=192$ hours (table 4), as follows:

Based on table 4, at the observation $t=$ 92 hours, the chemical compounds of Malathion and Profenofos were not detected. This shows that the concentration disturbance and Profenofos in the sample have broken down completely into simple compounds which are not contaminants. Prediction of Biodegradation of Malathion and Profenofos compounds according to the 
EAWAG-Biocatalysis and Biodegradation Pathway Prediction System that Malathion and Profenofos compounds will be degraded into simpler compounds, namely Hexadecanenitrile (CAS) chemical compounds Palmitonitrile, Palmitic acid nitrile, N-Hexadecanon 1- Cyanopentadecane which is the result of degradation of Profenofos. these compounds were detected at peak $=7$ and real time $=17,826$ and Hexadecanenitrile (CAS) at peak $=14$, real-time $=22,472$ (fig 13), chemical compound Anthracene-9-OI,9,10-Dihydro-10(4-Nitrobenzylideno)-(Functional Group-Ol/ Alcohol) was detected at peak 54, real time = 29,285 (fig 14), whereas chemical compound 2\{4- [2- (4-Methoxymethylphenyl) vinyl] phenyl\} propan-2-ol (functional group-ol / alhohol) with peak $=53$ and real time $=29,140$ (fig 15) and chemical compounds Acethydrazide compound, 2 (2-naphthylamino) -N2- (2,6-dichloro benzylideno) is a decomposed benzyl aldehyde group, is a compound resulting from Malathion degradation, detected with peak 4 and real time $=12,985$, as follow ${ }^{33}$ (fig 16) :

At the observation of $t=192$ hours, the chemical compounds of Malathion and Profenofos have been degraded into simpler and non-toxic compounds. ${ }^{37}$

\section{CONCLUSION}

The indigenous bacterial consortium Exiquobacterium profundum - Oceanobacillus iheyenis was able to completely degrade Malathion and Profenofos at observation $t=4$ (96 hours observation) based on a decrease in the area \% of Malathion from 7.37 to 2.25 and a decrease in area \% of Profenofos from 6.91 to 2, 21. At the observation $t=8$ (192 hours) Malathion and Profenofos compounds were not detected (area\% $=0$ )

\section{ACKNOWLEDGMENTS}

The researcher would like to thank all staff of the Integrated Laboratory of Diponegoro University, Semarang, and all staff of the Dian Nuswantoro University health laboratory, Semarang so that this research can be carried out well.

\section{CONFLICT OF INTEREST}

The authors declare that there is no conflict of interest.

\section{AUTHORS' CONTRIBUTION}

SI does the research design, wrote the research results, wrote the initial draft of the manuscript. SI and PSO worked together to manage the research analysis. SI manages the literature and makes final draft corrections. Both authors read and approved the manuscript for publication.

\section{FUNDING}

None.

\section{ETHICS STATEMENT}

Not applicable.

\section{DATA AVAILABILITY}

All datasets generated or analyzed during this study are included in the manuscript.

\section{REFERENCES}

1. Meftaul IM, Venkateswarlu K, Dharmarajan R, Annamalai $P$, Megharaj $M$. Pesticides in the urban environment: A potential threat that knocks at the door. Sci Total Environ. 2020;711:134612. doi: 10.1016/j.scitotenv.2019.134612.

2. Mova Al'Afghani M, Paramita D. Regulatory Challenges in the Phasing-Out of Persistent Organic Pollutants in Indonesia. Int Chem Regul Law Rev. 2018;1(1):12-27. doi: 10.21552/icrl/2018/1/5

3. Isworo S, Purwanto I, Sabdono A. Impact of pesticide use on organophosphorus and organochlorine concentration in water and sediment of Rawa Pening lake, Indonesia. Res J Environ Sci. 2015;9:233-40. doi: 10.3923/rjes.2015.233.240

4. Jensen IM, Whatling P. Malathion: A review of toxicology. Hayes' Handb Pestic Toxicol. 2010;1527-42. eBook ISBN: 9780080922010

5. Siddiqa A, Faisal M. Microbial degradation of organic pollutants using indigenous bacterial strains. In: Handbook of Bioremediation. Elsevier; 2021: 625-637. eBook ISBN: 9780128193839

6. Singh B, Kaur J, Singh K. Microbial degradation of an organophosphate pesticide, malathion. Crit Rev Microbiol. 2014;40(2):146-54. doi: 10.3109/1040841X.2013.763222

7. Geed SR, Kureel MK, Shukla AK, Singh RS, Rai BN. Biodegradation of malathion and evaluation of kinetic parameters using three bacterial species. Resour Technol. 2016;2:S3-11. doi: 10.1016/j. reffit.2016.09.005

8. Reza M, Fiza J, Hossen F, Ahmed F. Isolation and partial characterization of organophosphate pesticide degrading bacteria from soil sample of Noakhali, Bangladesh. Bangladesh J Microbiol. 2019;36(1):17-22. doi: 10.3329/bjm.v36i1.44263 
9. Cai X, Wang W, Lin L, et al. Autotransporter domain-dependent enzymatic analysis of a novel extremely thermostable carboxylesterase with high biodegradability towards pyrethroid pesticides. Sci Rep. 2017;7(1):3461. doi: 10.1038/s41598-017-035618

10. Nanda M, Kumar V, Fatima N, et al. Detoxification mechanism of organophosphorus pesticide via carboxylestrase pathway that triggers de novo TAG biosynthesis in oleaginous microalgae. Aquat Toxicol. 2019;209:49-55. doi: 10.1016/j.aquatox.2019.01.019

11. E Gonzales-Condori, S Ramírez-Revilla, J VillanuevaSalas. Role of Eisenia foetida in the degradation of profenofos in presence of native bacterial communities. Revista Mexicana De Ingeniería Química. 2020;19(Sup. 1): 45-57. doi: 10.24275/rmiq/IA1505

12. Kang $M$, Yang JS, Kim Y, Kim K, Choi H, Lee SH. Comparison of DNA extraction methods for drug susceptibility testing by allele-specific primer extension on a microsphere-based platform: Chelex-100 (inhouse and commercialized) and MagPurix TB DNA Extraction Kit. J Microbiol Methods. 2018;152:105-8. PMID: 30075237. doi: 10.1016/j.mimet.2018.07.019

13. Ye S, Zeng $\mathrm{G}, \mathrm{Wu} \mathrm{H}$, et al. Biological technologies for the remediation of co-contaminated soil. Crit Rev Biotechnol. 2017;37(8):1062-76. PMID: 28427272. doi: 10.1080/07388551.2017.1304357

14. Santosa GW, Djunaedi A, Susanto AB, Pringgenies D, Ariyanto $D$. Characteristics of bioactive compounds of Holothuria atra (Jaeger, 1833) associated bacteria. AACL Bioflux. 2020;13(4):2161-2169.

15. Gunasegar S, Neela VK. Evaluation of diagnostic accuracy of loop-mediated isothermal amplification method (LAMP) compared with polymerase chain reaction (PCR) for Leptospira spp. in clinical samples: $A$ systematic review and meta-analysis. Diagn Microbiol Infect Dis. 2021;100(3):115369. doi: 10.1016/j. diagmicrobio.2021.115369

16. Lee PLM. DNA amplification in the field: move over PCR, here comes LAMP. Wiley Online Library. 2017;17(2):138-141. doi: 10.1111/1755-0998.12548

17. Vasiee AR, Mortazavi A, Tabatabaei-yazdi F, Dovom MR. Detection, identification and phylogenetic analysis of lactic acid bacteria isolated from Tarkhineh, Iranian fermented cereal product, by amplifying the 16s rRNA gene with universal primers and differentiation using rep-PCR. Int Food Res J. 2018;25(1):423-432.

18. Protopopova M, Pavlichenko V, Gnutikov AA, Chepinoga V. DNA barcoding of Waldsteinia Willd. (Rosaceae) species based on ITS and trnH-psbA nucleotide sequences. In: Information Technologies In the Research Of Biodiversity. 2019:107-115. doi: 10.1007/978-3-030-11720-7_15

19. Kim YG, Choi DH, Hyun S, Cho BC. Oceanobacillus profundus sp. nov., isolated from a deep-sea sediment core. Int J Syst Evol Microbiol. 2007;57:409-413. PMID: 17267988.

20. Mello B. Estimating timetrees with MEGA and the TimeTree resource. Mol Biol Evol. 2018;35(9):2334-42. PMID: 29931306. doi: 10.1093/molbev/msy133

21. Tony AM, El-Geundi MS, Hussein SM, Abdelwahab MZ. Degradation of malathion in aqueous solutions using advanced oxidation processes and chemical oxidation. Direct Res J Agric Food Sci. 2017;5:174-85. ISSN: 23544147. doi: 10.26765/DRJAFS

22. Ozdemir C, Ozdemir S, Oz E, Oz F. Determination of organochlorine pesticide residues in pasteurized and sterilized milk using QuEChERS sample preparation followed by gas chromatography-mass spectrometry. J Food Process Preserv. 2019;43(11):e14173. doi: 10.1111/jfpp.14173

23. Tilahun B, Tesfaye A, Muleta D, Bahiru A, Terefework $Z$, Wessel G. Isolation and molecular identification of lactic acid bacteria using 16s rRNA genes from fermented Teff (Eragrostis tef (Zucc.)) dough. Int J food Sci. 2018;2018:8510620. doi: 10.1155/2018/8510620 24. Green MR, Sambrook J. Analysis of DNA by agarose gel electrophoresis. Cold Spring Harb Protoc. 2019. doi: 10.1101/pdb.top100388

25. Quammen $\mathrm{D}$. The tangled tree: a radical new history of life. Simon and Schuster. Nature. 2018;560:26-27. doi: 10.1038/d41586-018-05827-1

26. Sarjono PR, Hazrina QH, Saputra A, et al. Isolation, characterization, and identification of endophytic bacteria by $16 \mathrm{~S}$ rRNA partial sequencing technique from leaves of carica papaya and its potential as an antioxidant. AIP Conference Proceedings. AIP Publishing LLC; 2020:20053. doi: 10.1063/5.0005715

27. Goncalves LR, Herrera HM, Nantes WAG, et al. Genetic diversity and lack of molecular evidence for hemoplasma cross-species transmission between wild and synanthropic mammals from Central-Western Brazil. Acta Trop. 2020;203:105303. doi: 10.1016/j. actatropica.2019.105303

28. Challa S, Neelapu NRR. Phylogenetic trees: applications, construction, and assessment. Essentials Bioinformatics. 2019;(3):167-92. doi: 10.1007/978-3030-19318-8_10

29. Newman R, Gilbert MW, Lothridge K. GC-MS guide to ignitable liquids. CRC Press; New York. 2020. doi: 10.4324/9781003067917

30. Sivakumar S, Anitha P, Ramesh B, Suresh G. Analysis of EAWAG-BBD pathway prediction system for the identification of malathion degrading microbes. Bioinformation. 2017;13(3):73-77. doi: 10.6026/97320630013073

31. Eawag BH. Swiss Federal Institute of Aquatic Science and Technology. Switzerland, 2014.

32. El-Nahhal Y. Toxicity of some aquatic pollutants to fish. Environ Monit Assess. 2018;190:449. PMID: 29974249. doi: 10.1007/s10661-018-6830-0

33. Kumar SS, Ghosh P, Malyan SK, Sharma J, Kumar V. A comprehensive review on enzymatic degradation of the organophosphate pesticide malathion in the environment. J Environ Sci Heal Part C. 2019;37(4):288329. doi: 10.1080/10590501.2019.1654809

34. Lozowicka B, Rutkowska E, Jankowska M. Influence of QuEChERS modifications on recovery and matrix effect during the multi-residue pesticide analysis in soil by GC/MS/MS and GC/ECD/NPD. Environ Sci Pollut Res. 2017;24(8):7124-38. doi: 10.1007/s11356-016-8334-1

35. Baron S. Medical microbiology. 4th Ed. University of Texas Medical Branch at Galveston; 1996. ISBN-10: 0-9631172-1-1. 